\title{
Navigating the Night Sea Journey: Learning to Let Go after Tenure's Loss
}

\author{
Stephen Bragaw, Washington and Lee University
}

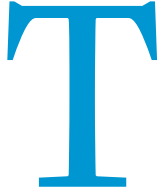
he morning of March 3, 2015, I arrived at my office to get ready to teach my first class of the day at the college where I had taught for 21 years. By noon, the president had announced to the faculty and then the students that the college would close at the end of the semester. To say this was sudden and a shock is an understatement. As I passed through the gates shortly thereafter on my way home, the magnitude hit me like a train: we had 70 days until the end of the semester. I had to place my students, help my colleagues in my department, pack up my office and, most important, get a new job. In the two decades since leaving graduate school, I had steadily risen through the ranks to tenure and to full professor. I was awarded a named chair in recognition of teaching excellence, while also heading the politics department for 10 years and serving the wider institution in manifold ways. I had carved out an individual role and built a department of which I was proud. In a little more than two months, all that would be gone.

\section{THE CHANGING NATURE OF TENURE AND THE "CRISIS" IN HIGHER EDUCATION}

The debate about whether there is a "crisis" in higher education is not hypothetical to me: the problem with the premise of that debate is that there is not "a" crisis but many interconnected ones.

My focus is on the changing nature of tenure. Tenure as the normative situation of those who work as professors has receded precipitously during the past 30 years (Wilson 2010). How is this decline changing not only the institutional work of higher education but also the lived experience of being a professor? Mine is not a universal tale: far from it. It is the peculiar story of having tenure but losing it to events outside of my control. The particulars were defined by the unique circumstances of one small liberal arts college's sudden movement toward closure. Yet, as a political scientist living through a scenario of sudden institutional crisis, I gained insight into what tenure is and how it works individually and collectively.

Three themes emerged. I saw how tenure works as a social contract, addressing common problems inherent in institutional governance through creating horizontal relationships and a sense of the future. I felt how tenure confers status privilege that, although bowing toward internal growth and freedom, is deeply contextualized in external validation. I experienced how tenure creates identity in much the way that Swiss psychologist Carl Jung defined persona. Jung's archetype metaphor for how we cope with loss of identity-the "night sea journey"-became instrumental in moving forward.

\section{Tenure as a Social Contract}

Part of what kept me sane during the closure was keeping myself mindfully aware of and curiously observant to what happens to the social system and culture of an institution when it is suddenly coming to an end. As academics, we spend much time working toward and arguing about tenure. As political scientists, many of us study the normative and empirical dimensions of institutions and institutional change, how rules and systems incentivize behavior within institutions, and how culture and narratives knit individuals and institutions together. As fate would have it, the week of the announcement, we were reading in my senior seminar Daniel Drezner's book stress-testing international relations theory with scenarios of zombie apocalypse (Drezner 2014). To me, the extremity of our situation called for dark humor: I jokingly thought that if zombies were seemingly attacking the college, what did this tell me about the unstated and tacit assumptions about how a college worked?

Tenure's utility revealed itself with a brutal efficiency in its sudden communal, impending absence. Tenure functions in part as a social contract to solve the collective-action problems inherent in the American approach to faculty governance: the lack of a natural incentive to cooperate. Tenure creates the incentives for trust and comity to emerge. This is a horizontal as well as a vertical exchange. I had understood tenure only vertically: as a relationship between me and the institution, in which I got academic freedom and certainty of employment, without thinking about what the institution got out of it, what it cost me, and how it defined how I related with others.

The horizontal nature was revealed: tenure creates lateral relationships that forge the basis for mutual cooperation, to manage competing interests and agendas, and to ensure the difficult work of binding the life of the institution together. Tenure creates the incentive to get along by creating a shared sense of future, allowing favors to be asked and granted and short-term losses balanced against the promise of future returns. Honor systems can work. Collective work is accomplished. Without that future, cooperation, comity, and trust can break down quickly. Once lost, they are extremely difficult to replenish.

By its unique circumstances, institutional failure or turnaround is an extreme example. However, as tenure continues to broadly decline, the commodities of cooperation and comity within wider scholarly and professional communities will 
become scarcer, changing the social contracts and functioning of these communities in important ways over time.

\section{Tenure as a Privileged Status}

A second hard truth learned was how tenure creates privileged status and how that works on the individual and the group. rather than a tenured professor. My family was not significantly uprooted; it could have been much worse. Neighbors dubbed me "the guy who landed on his feet." It seemed like a new beginning-a clean break in my narrative.

This is my story, not the institution's. Yet, when the college just as suddenly and surprisingly went through the process of

\section{I had understood tenure only vertically: as a relationship between me and the institution, in which I got academic freedom and certainty of employment, without thinking about what the institution got out of it, what it cost me, and how it defined how I related with others.}

Fresh in my mind from class was the debate between Glaucon and Socrates in the second book of Plato's Republic about the worth of justice (Plato 1991). Glaucon argues that the value of justice is the externally conferred benefit-the reputation of being just. Socrates argues that the reward is internally won-a harmonious soul. Was the value of tenure in the externally conferred privileges? Or was its real value internal?

To me, the answer was complicated. If I said it were purely internal, I would not be honest. The collective and individual privilege that tenure bestows is powerful, tangible, and very real. The allure of security can be mesmerizing. Like any form of privilege, though, it is dangerous when its status is opaque to the holder-not to mention incredibly jarring if it is lost. Yet, in stripping away the externally conferred benefits, the internally generated value was finally revealed to me. Whereas the title was theirs and the status could be revoked by others, the habits and discipline to do the work I had done was and would always be mine. I took that forward with me.

As tenure recedes, academics in general and political scientists in particular need to have an honest discussion about the privilege that tenure creates and how that shapes work and power not only institutionally but also in our individual lives. The privilege creates the conditions for academic freedom, which is undeniably good; however, it confers far more, and an honest discussion of that would benefit all.

\section{Tenure as a Jungian Persona}

Third, I learned how tenure became enmeshed in my identity, acting much like what Carl Jung called a persona. "Persona" is the Latin name for the masks that an actor wears on the stage in drama or comedy: personas to Jung were the "masks" that we acquire in life that collectively form our identity (Jung 1983, 66). To Jung, our personas are defined by the narratives we create to explain and understand our own life, much as the play is defined by the masks of the actors. For me, tenure created a powerfully dominant and comprehensive persona.

If mine is not a universal story, it is most certainly not a tale of woe. I was extraordinarily lucky: about an hour and a half after the college's closure was announced publicly, I got a call from a colleague at a nearby elite liberal arts university about an opening. By the end of the week, I had the preliminary offer for the job I currently hold: I am now a visiting trying to reopen after a series of successful lawsuits, the new president offered me my old job back. I chose not to return. It was a complicated decision, rooted deeply in my personal experience of the time partially described previously. It was the right decision for me and my family, and I have no regrets. However, the chance for a clean break was gone. To embrace the narrative of "landing on my feet," I had to contend against the externally imposed narrative of "the person who did not go back." Years later, I still am asked why.

To say it was the easiest decision I have ever made is the truth but not the whole truth: that would mask the anxiety, anger, depression, and post-traumatic stress that naturally followed. I went through a "crisis of the middle," as described by Carl Jung, as my mind reacted to the sudden jarring loss of a major component of my persona. It ended when I learned to truly let go and embrace a new, healthier, and broader sense of self.

In the early twentieth century, Jung wrote extensively about crisis in the middle of life (Jung 1983, 72-4). Jung's interest came not only out of his theory of identity, consciousness, and the "collective unconscious" but also from his own experience. Jung's "crisis of the middle" came for personal and professional reasons. He experienced a profound falling out with his early mentor, Sigmund Freud, over Freud's unwillingness to accept Jung's work on the unconscious and identity (Jung 1983, 58). At the same time, he made the decision to resign his post as a university lecturer and to focus full time on his work in analysis with patients. For the times, this was a radical departure. Jung experienced profound personal disruption and unease because of this, even though he knew it was the right course for him.

The experience helped him refine his theory of personality. What marks the first half of life, to Jung, is acquiring or being given personas-identities created by the roles we play in life. Some are given, others we pursue, but-as they accrue-they carry weight, as the individual persona is what it is: a mask. It is representative of part of the whole but it is not the whole itself. Over time, some become the primary way of seeing ourselves and, as we add to them, we drive other parts of our personality into our unconscious. Not all parts of the persona fit together, the edges do not necessarily mesh, and they create competing demands on our time and energy that create conflict within the self. 
To Jung, the beginning of the second half of life is when we begin to lose personas: some we give up, others come to their natural conclusion or are taken away from us against our will. The loss of persona is inevitable. The crisis, to Jung, is in how we choose to react. If we cling to that which we have lost, it is an immediate path to internal suffering as well as public ridicule. Nobody gets through the middle without a trip to the hospital, the courthouse, the unemployment office, or the graveyard. Death of parents, maturation of children into adulthood, divorce, disease, and job loss all threaten identity by robbing a person of a persona. This can be devastating because individuals literally are losing part of their own self-perception.

It was not until it was suddenly taken away that I realized how dominant the tenured-professor persona had been for me. his restlessness. Upon getting hit by the killing curse a second time, Harry Potter journeys to a mystical train station and communes with the ghost of Professor Dumbledore, gaining the freedom from his status as the "chosen one" and the power to choose his destiny. He gives up his grief and fear of death and gains the wisdom to fully defeat Voldemort (Rowling 2007).

Dante undertakes perhaps the most vivid night sea journey, beginning with the epic opening line of The Divine Comedy (Alighieri 2003, 1):

Midway upon the journey of our life

I found myself within a forest dark

For the straightforward pathway had been lost.

Ah me! How hard a thing it is to say

What was this forest strange, rough, and stern,

Which in the very thought renews the fear.

\section{The key, for Jung, was to be able to let go: let go of the fragments of a shattered persona and let the identity of the self re-form, particularly in ways that allow those portions of the personality driven down into the unconscious by the old persona to emerge and find voice.}

\section{NAVIGATING THE NIGHT SEA JOURNEY}

The key, for Jung, was to be able to let go: let go of the fragments of a shattered persona and let the identity of the self re-form, particularly in ways that allow those portions of the personality driven down into the unconscious by the old persona to emerge and find voice. This is the process of aiming the self toward fulfillment, which is internally regarding, as opposed to achievement, which is externally regarding. To Jung, the guides in this process are the "archetypes" found in our collective mythology and stories: elements of life experience that take on the appearance of "universality."

One key archetype to Jung was the "night sea journey"the descent into death or the underworld by the heroic figure, in which individuals confront their greatest fear and converse with the dead, who guide them onto a new course of their life. Jung wrote in The Psychology of the Transference: "The night sea journey is a kind of a descensus ad inferos-a descent into Hades and a journey to the land of ghosts somewhere beyond this world, beyond consciousness, hence an immersion in the unconscious" (Jung 1983, 83-4). These are epic experiences of mythic journey, undertaken at great peril. Yet, they are utterly transformative, arming individuals with a new understanding of life and their own power. By descending into death, rebirth becomes possible.

Examples of the night sea journey in literature abound. The prophet Jonah runs away from his calling and flees to the far west, only to nearly drown in a calamitous storm and be swallowed by a great fish, who carries him east and disgorges him onto the path for which he was called to be. He learns to give up doubt and his desire to control the outcome. Odysseus descends into the underworld to find the true path to home to face strife and to leave again. He learns to gives up
Guided by the ghost of Virgil, Dante descends into the inferno and then up the mountain of purgatory to exit into paradise. He gives up his grief over the loss of his beloved in this life to be reunited with her in the next.

In retrospect, I am sad to report that I had no spirit guides, no ghosts of Roman poets or dead wizard-mentor professors to illuminate my path. I feel cheated. However, I completely understood Jung's metaphor. My crisis of the middle ended when I let my old professor persona die fully and let grief run its course. I learned to genuinely smile when reminded kindly (or not) of the change. I let go of not only the old externally conferred statuses and privileges but also the ways those externally controlled had defined how I saw and valued myself internally. Truly letting go was incredibly difficult, but it was powerfully and wonderfully transformative. My imposter syndrome completely disappeared. I was surprised as a new and very different internal sense of pride and gratitude emerged.

I navigated my night sea journey. I lost tenure, but I also lost my fear of not being able to survive professionally or to be happy, confident, and productive without it. I faced the worst day one can have in higher education not defined by violence: I not only did not die, I also learned to thrive and move forward. In the end, Socrates won over Glaucon. The value of tenure was internal.

\section{CONCLUSION}

As tenure status continues to decline as the "normal" experience of being a professor, the social contract that once knit together individuals, institutions, and associations becomes less cohesive. At the same time, the social narratives used to define individual success and accomplishment as well as 
institutional growth and advancement become increasingly out of whack with the lived individual experiences and institutional realities of those who work in higher education. As political scientists, we understand that the divergence between institutional norms and individual expectations creates cognitive dissonance and is a recipe for crisis. Without honest conversation, drawing respectfully on different types of experiences, the dissonance will only grow the more the narrative of success and the lived reality diverge, at great personal and institutional cost. That is a development that can only bear a bitter harvest over time.

\section{ACKNOWLEDGMENTS}

The author thanks Jennifer Diascro, Judith Grant, and Susan Sterett for organizing the National Science Foundationsponsored workshop, "Advancement Through Narrative: Understanding and Navigating Success and Failure in the Academy" (NSF Grant \#1643084), and the workshop participants for their insights on and encouragement for an earlier version of this article; Dean Robert Straughan, Lucas Morel,
Mark Rush, and my colleagues in the Department of Politics at Washington and Lee University for their support and encouragement; and to Spencer Bakich, John Casteen, and David Griffith for their friendship, comments, and encouragement. Onward! -

\section{REFERENCES}

Alighieri, Dante. 2003. The Divine Comedy: The Inferno, The Purgatorio, and The Paradiso. Translated by John Ciardi. Berkeley, CA: Berkeley Press.

Drezner, Daniel. 2014. Theories of International Relations and Zombies (revised edition). Princeton, NJ: Princeton University Press.

Jung, Carl G. 1983. The Psychology of the Transference. London: Routledge.

Jung, Carl G. 2013. The Essential Jung. Selected and introduced by Anthony Storr. Princeton, NJ: Princeton University Press.

Plato. 1991. The Republic of Plato. Translated by Allan Bloom. New York: Basic Books.

Rowling, J. K. 2007. Harry Potter and the Deathly Hallows. New York: Harcourt.

Wilson, Robin. 2010. "Tenure, RIP: What the Vanishing Status Means for the Future of Education." The Chronicle of Higher Education. July 4. Available at www.chronicle.com/article/Tenure-RIP/66114. 